\title{
E-Commerce Shopping Gets Real: The Rise of Interactive Virtual Reality
}

\author{
Satish R. Billewar', Karuna Jadhav², D. Henry Babu³ and ${ }^{4}$ Sunil Ghane \\ ${ }^{1}$ Vivekanand Institute of Management Studies \& Research, Mumbai, India \\ ${ }^{2}$ Neville Wadia Institute of Management Studies \& Research, Pune, India \\ ${ }^{3}$ St. Francis Institute of Management and Research, Mumbai, India \\ ${ }^{4}$ Sardar Patel Institute of Technology, Mumbai, India
}

\section{ABSTRACT}

Virtual Reality is considered to be the technology that will be used very extensively. The paper discusses the idea of the implementation of virtual reality in E-commerce. The shopper can virtually walk through the aisles of the store, stop and examine an item. The photos, textual information, support this examination process, and audio clips that describe the item. Depending on the photos' completeness, the shopper can virtually touch and examine the merchandise from all angles, and the order can be placed into the shopping cart. The paper is an effort to give the customer a more realworld shopping experience without going outside. It also makes shopping online more attractive and reliable. The user can have the store experience by looking for the items from the isles and have a better experience in evaluating the items by having the ability to pick them up like in actual stores.

KEY WORDS: VIRTUAL REALITY, E-COMMERCE, VIRTUAL STORE, CUSTOMER SATISFACTION, SHOPPING CART.

\section{INTRODUCTION}

The virtual store's experience is also enhanced by an augmented reality assistant that helps the users by giving them all the information needed in audio form or using its avatar. One primary advantage of having a virtual store is its possibility of the plugin the store in different games targeting the virtual video game players. They could be more interested in the idea of buying products even while playing their favorite game and could order their merchandise from an e-commerce store within the game. The satisfaction from the virtual immersion is enormous as everything can be customized according to the user, like crowd, products, and interaction satisfaction during shopping can be given without any hassle.

Biosc Biotech Res Comm P-ISSN: 0974-6455 E-ISSN: 2321-4007 Corresponding author email:

\section{crossef}

Identifiers and Pagination

Year: 2021 Vol: 14 No (5) Special Issue

Pages: $130-132$

This is an open access article under Creative

Commons License Attribn 4.0 Intl (CC-BY). DOI: $h t t p: / / d x$.doi.org/10.21786/bbrc/14.5/25

2. Concept Discussion: Virtual reality has been one of the emerging technologies that have existed for a long time as a concept. From medieval panoramic paintings to Morton Heilig'sSensorama patented in 1962, the point of virtual reality is to trick someone's brain into believing something is real, even when it isn't. Virtual Reality application has always been in some kind of simulation like flight simulation or in movie watching. These both have existed from the early 1900s, with the first flight simulator built-in 1929 by Edward Link and Sensorama (1962), which was used for movie watching.

3. Existing System: The existing system is mostly browserbased with functionalities like Superpose an item from the shopping cart into the Audio/Visual Virtual Tour. So that the shopper can "see' that item on the shelf of the store. The shopper can "pick up that item, examine it by viewing additional images and textual descriptions and pricing data, and even asking a clerk a specific question. Finally, if desired, place the item into their shopping cart.

Figure. 1 shows the software stack of the virtual reality shopping software components and will be referenced when discussing the main functions of the virtual reality

Article Information

Received: $20^{\text {th }}$ Jan 2021 Accepted after revision: $30^{\text {th }}$ Mar 2021 
shopping software; the main component is the heart of the Virtual Shopping Experience.

1. Helps to coordinate all the function and features of the other four components.

2. Adds function and feature to provide the complete Shoppers' Virtual Reality Shopping Experience.

To best understand this last component's function and feature, we will consider what must be delivered to the shopper, as viewed by the shopper.

Thevirtual reality shopping tightly integrates the features of the Audio/Visual Virtual Tour Software, Shopping Cart Software, the variety of media data, and optionally the 3-Dimensional (3D) Virtualization Software. By building upon these components in such a way as to add features specific to the Virtual Reality Shopping Experience. One such example is to Superpose an item from the shopping cart into the Audio/Visual Virtual Tour Software.So that the shopper can "see' that item on the shelf of the store. The shopper can "pick up that item, examine it by viewing additional images and textual descriptions and pricing data, and even asking a clerk a specific question. Finally, if desired, place the item into their shopping cart.

Figure1: Existing System

\begin{tabular}{l|l|}
\hline Internet Access for & Shopping Cart Interface \\
Virtual Reality Sbopping & \\
\hline
\end{tabular}

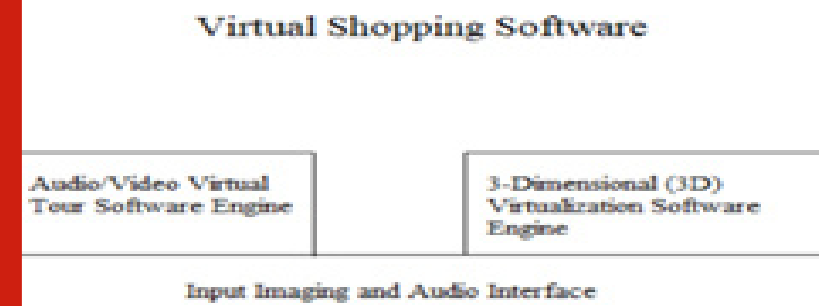

4. Proposed System: The proposed system is an updated version of the existing version with a virtual reality headset giving more immersion than the traditional mouse and keyboard.Virtual Reality headset gives the user more unrestricted movement and a 3600 view of the shopping center. The movement allows the user to have a real shopping experience like walking to the products, etc.This architecture can be integrated into any open-world game like GTA to enable users to buy from in-game shops for real life. It allows the companies to sell their merchandise even through in-game shops, which will most certainly increase sales.

Figure 2 represents how the virtual store can be connected to a video game's in-game store. The flow of the in-game shops will be once you enter the shop, the game redirects your avatar to a virtual e-commerce showroom where you can search for the product you want, and an augmented reality character guides you to that product. Once you get to the product, you can try it on, and if you like it, you can proceed to the counter and carry the payment. The payment can be through credit card or through in-game currency you have previously bought, like UC in PUBG. This feature gives the game developers an additional income stream which is beneficial. The seamless transition from the game to the virtual store needs to handle through a gateway that connects the game to the virtual store only when the user enters the in-game store.

It allows the game to run more realistically to be affected by the e-commerce site's traffic. The user's cache memory to personalize the user's experience in the software can also be used in the video-game to advertise and make the user aware of the deals even when he is playing. Still, at the same time, there is a need for awareness amongst the developers and e-commerce sites that over an advertisement that affects the users' gaming experience will negatively impact the number of visits to the virtual store by the user.

\section{Figure 2: Proposed System}

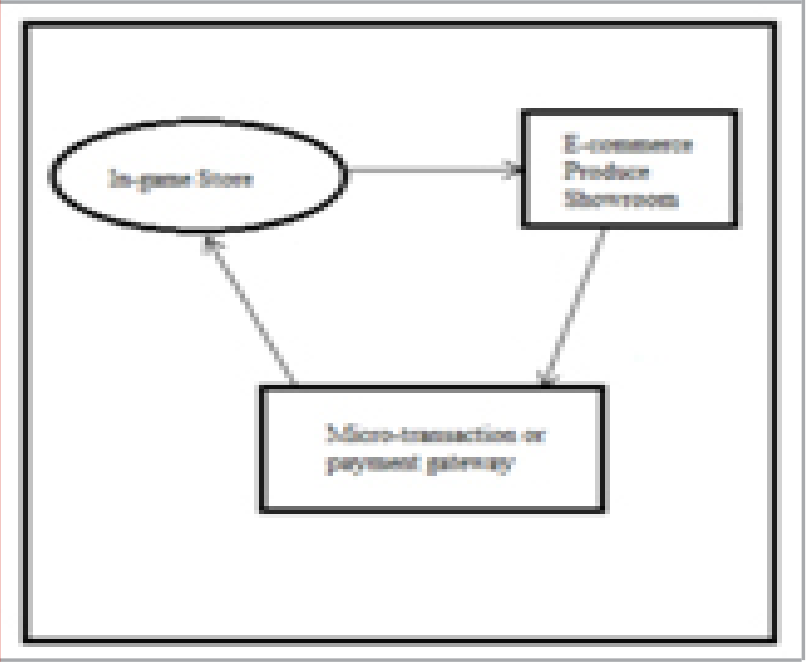

\section{CONCLUSION}

We examined the implementation of Virtual Reality in E-commerce, which would provide users with the immersive experience of real-world shopping experience on a virtual e-commerce platform. Implementing such a system is quite possible as the hardware technology required for such a system is readily available.The software technology required for augmented reality and virtual reality is also available and has been implemented separately. The only implementation that needs to be done is to merge these existing technologies into one. The increasing number of VR users could help test the Beta version of this platform and make it ready for the broader market.The consumer satisfaction is high as during an experiment; the users were more focused on shopping in when virtual environment than in reality because there wasn't any external factor interfering. 


\section{REFERENCES}

Catherin Lin-Hendel," System and method for constructing and displaying active virtual reality cyber malls, show rooms, galleries, stores, museums, and objects within", Patient Appl. No.: 09/631,238

Christian Peukert, Jella Pfeiffer, Martin Meißner, Thies PfeifferAndChristofWeinhardt, "Shopping in Virtual Reality Stores: The Influence of Immersion on System Adoption”,Journal of Management Information Systems / 2019, Vol. 36, No. 3, pp. 755-788

Dr. Sanjay Mishra, CharuRastogi, "Future of E-commerce in India",Studies in Indian Place Names (UGC CARE Journal), ISSN: 2394-3114, Vol-40-Issue-69-March2020

Elliott Glazer, CarolLee Hobson, Elizabeth Sandra Deming, Coby Royer, Jeffret Scott Fehlhaber, "Virtual reality shopping experience", Patient Appl. No.: 12/693,294

Gabriele Pizzi, Daniele Scarpi, Marco Pichierri, Virginia Vannucci, "Virtual reality, real reactions: Comparing consumers' perceptions and shopping orientation across physical and virtual-reality retail stores", Computers in Human Behavior, Elsevier

IAMAI Report, "Internet penetration in India”, https://
cms.iamai.in/Content/ResearchPapers/d3654bcc-002f4fc7-ab39-e1fbeb00005d.pdf

"India Brand Equity Foundation”, https://www.ibef.org/ industry/ecommerce.aspx

Kun Chang Lee, Namho Chung, "Empirical analysis of consumer reaction to the virtual reality shopping mall", Computers in Human Behavior 24 (2008) 88-104

Mark Yi-CheonYim, Shu-Chuan Chu, Paul L. Sauer, "Is Augmented Reality Technology an Effective Tool for E-commerce? An Interactivity and Vividness Perspective", Journal of Interactive Marketing, 2017, vol. 39, issue C, 89-103

Michael Vincent Di Stefano, "Virtual Reality Shopping System", Patient Appl. No.: 11/355,210

S. R. Billewar, D Babu Henry (2012), "Performance Evaluation of E-Commerce Websites in India", International Journal of Computer Science and Information Technologies, Vol 3 (6), pp 5416-5418

Zhenhui Jiang, IzakBenbasat, "Virtual product experience: effects of visual and functional control of products on perceived diagonasticity and flow in electronic shopping", Journal of Management Information Systems, vol. 21, No.3, Winter 2004-5, pp. 111-147. 